\title{
$\mathrm{PH} 96$
}

\section{HELPS, autocostrucción colaborativa y ecológica}

HELPS Humanity Earth Life Population Solidarity es un proyecto Erasmus Plus que, desde septiembre de 2017, pretende adaptar, en territorios de Francia, Grecia, Italia y España, un sistema de intervención en edificaciones que favorezca la formación en autoconstrucción y la creación de vínculos locales. Surgido de un planteamiento piloto desarrollado en la región francesa de Normandía, en la actualidad el proyecto aglutina a diversas entidades europeas especialistas en bioconstrucción, preservación medioambiental y cohesión social.

Arturo Jiménez Viera, José Daniel Rodríguez Mariscal, Juan Javier Usero Fernández | Asociación Taph Taph Jorge Moya Muñoz | Asociación Taph Taph, Universidad de Sevilla ${ }^{1}$

URL <http://www.iaph.es/revistaph/index.php/revistaph/issue/view/4278>

El proyecto está promovido en España por la Asociación Taph Taph Bioconstrucción, Arquitectura y Paisaje Holístico (www.taphtaph.org) que asume el reto de conseguir una adaptación integral del proyecto en los ámbitos social, cultural, político y ambiental. Bajo la coordinación de la Asociación francesa Les 7 Vents, en este proyecto, además de la asociación española, participan: Mediterranean Centre of Environment en Grecia; Associazione nazionale cittá della terra cruda y Networking Education \& Training en Italia; y Enerterre, responsable de la base metodológica del proyecto, en Francia. Juntas trabajan desde septiembre de 2017.

Los objetivos generales de HELPS (www.helpsproject. eu) son tres:

> Promover la autoconstrucción colaborativa y ecológica, de edificaciones construidas en tierra mediante la puesta en valor y recuperación de técnicas constructivas tradicionales que mejoren las condiciones de habitabilidad a partir de la participación de la población local y el apoyo técnico de profesionales en el ámbito de la construcción.

> Desarrollar lazos sociales locales y prácticas solidarias, para crear una red de ayuda a personas en situación de precariedad.

> Potenciar el uso de materiales locales de construcción y de bajo impacto ambiental, promoviendo la economía y el emprendimiento local.

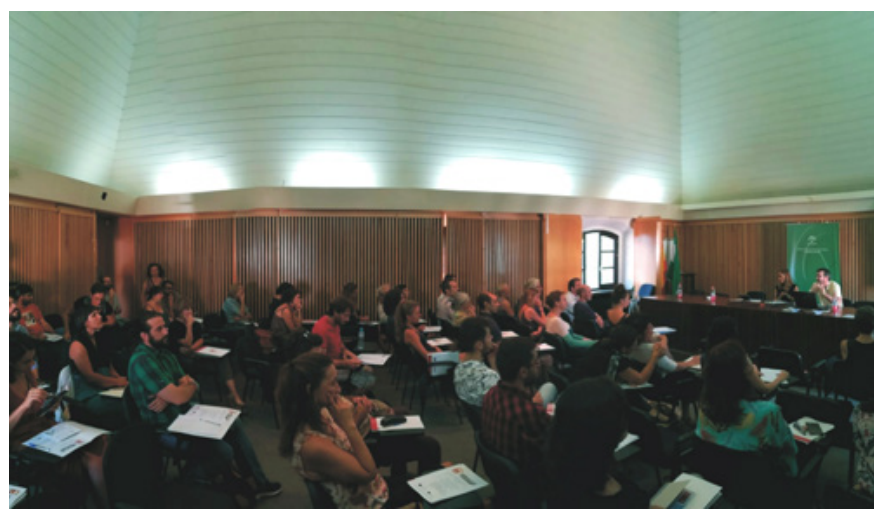

Presentación del proyecto HELPS en el IAPH

De manera específica su labor se concreta en: impulsar obras participativas de autoconstrucción de edificios, especialmente construidos en tierra; servir de soporte técnico y humano en las intervenciones de mejoras de edificios, a personas en situación de pobreza energética, independientemente de las condiciones de tenencia del edificio; facilitar un sistema de intercambio local que apoye los proyectos de mejora de edificios; promover el uso de materiales locales (tierra, fibras vegetales, cal, maderas, etc.) y el desarrollo de técnicas de construcción tradicionales (revestimientos de tierra, calicostrado, reparación de tapia, etc.) y la involucración de profesionales procedentes del ámbito local; cooperar con otros actores del ámbito público en la implementación del proyecto: instituciones, entidades sin ánimo de lucro y profesionales; proveer un lenguaje común y mantener un adecuado nivel de información y comprensión en el desarrollo de los proyectos. 


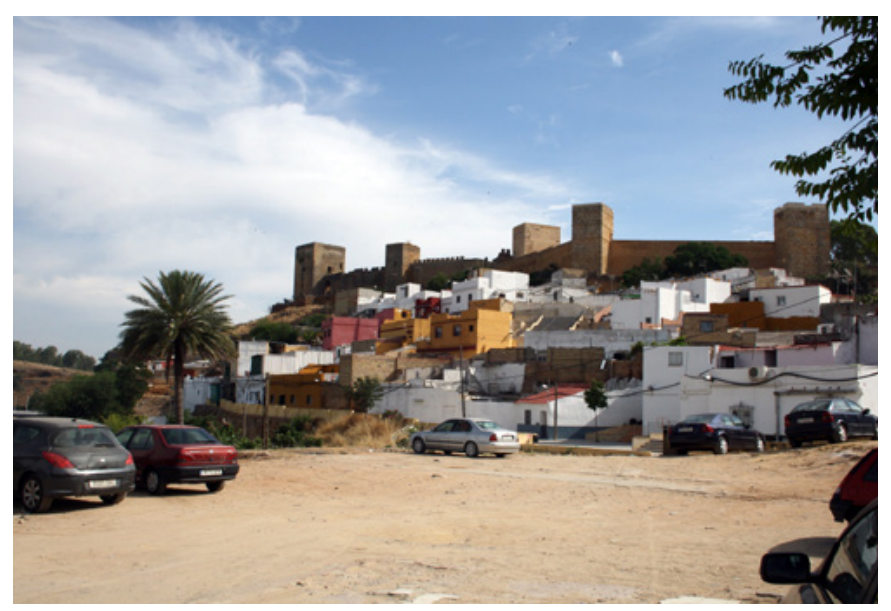

Barrio del Castillo de Alcalá de Guadaíra (Sevilla)

Para desplegar el proyecto en un contexto local, se hace necesario que las edificaciones sobre las que se interviene sean habitadas por personas en situación de pobreza energética; que la ejecución de las obras implique la participación de beneficiarios, voluntarios y técnicos profesionales; y que se empleen materiales locales y se potencien las técnicas de construcción tradicionales de la zona, se asegure la compatibilidad estética y funcional con la arquitectura vernácula sobre la que se interviene.

Para el desarrollo del proyecto se han creado tres herramientas comunes a las entidades socias: un acuerdo de colaboración, una guía de actuación y un repositorio de trabajos realizados.

\section{Acuerdo de colaboración y un sumario del proyecto}

El acuerdo de colaboración es un marco de trabajo para combatir la precariedad en edificaciones en mal estado de conservación y habitabilidad. Esta declaración de principios pretende ser consignada por todas las entidades multiplicadoras, de tal manera que se garantice la coherencia de sus proyectos locales. El sumario del proyecto aporta claves para el desarrollo de la oferta de formaciones, en materia de construcción con tierra, adaptadas a cada territorio.

\section{Guía de identificación y preparación de Obras}

Basada en la experiencia de seis lugares de experimentación (2018-2020), facilita una guía, para las futuras

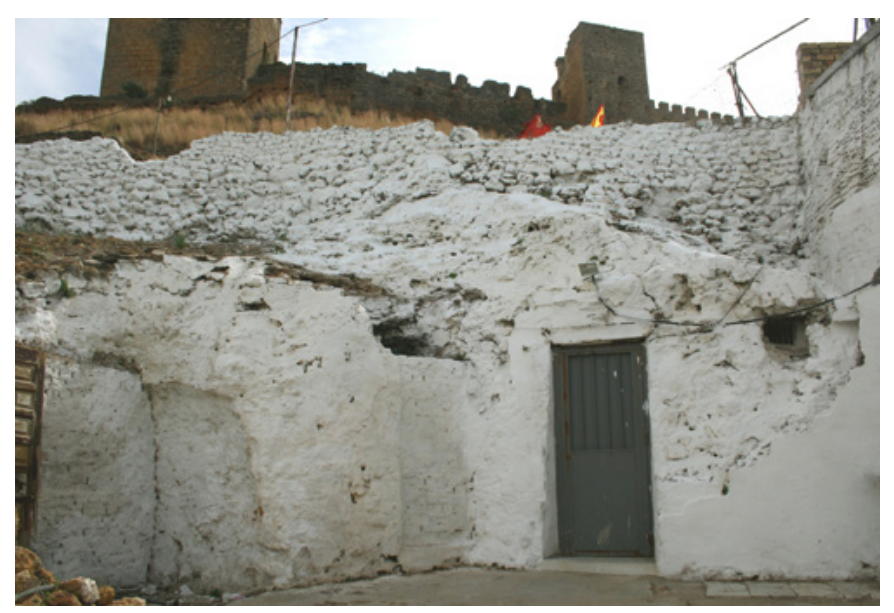

Casa cueva en el barrio del Castillo de | fotos Asociación Taph Taph

entidades multiplicadoras del sistema, en la implementación de acciones de renovación en edificaciones antiguas y hábitats de tierra con habitantes en dificultades socioeconómicas.

\section{Repositorio de habilidades con descripciones documentadas}

Se espera que al menos una entidad socia de cada país adquiera las capacidades y asegure la coherencia del proyecto, garantizando la continuidad mediante la formación especializada de personas y grupos locales en construcción con tierra así como en la coordinación técnica de las obras participativas.

La implementación del Proyecto HELPS supone un reto que debe afrontar dificultades derivadas del desconocimiento y la desprotección que afecta a la construcción tradicional y del desplazamiento de la arquitectura vernácula en favor de otras tipologías constructivas. Y este reto ha de ser entendido desde la colectividad, la cooperación y la transversalidad de forma que se equilibren los hábitats más desfavorecidos a la vez que se asegura la trasmisión patrimonial.

\section{NOTA}

1. Becario FPI. HAR2016-78113-R. Ministerio de Ciencia, Innovación y Universidades. Fondo Social Europeo. 